\title{
O LUGAR DA GEOGRAFIA NAS CIÊNCIAS E A QUESTÃO DA PERMANENTE RECONSTRUÇÃO DOS CONCEITOS GEOGRÁFICOS
}

\section{The place of Geography in sciences and the question of the permanent reconstruction of the geographic concepts}

\author{
Edu Silvestre de ALBUQUERQUE ${ }^{1}$
}

\section{RESUMO}

A evolução do estatuto da ciência geográfica no concerto das ciências e sua relação com a construção de um saber "espacial" reconhecido socialmente formam a temática central deste ensaio. A constante produção de novos conceitos para as tradicionais categorias geográficas situa-se exatamente nessa dialética entre a construção de uma ciência geográfica autônoma e a evolução das hierarquias científicas; e cuja síntese estaria num saber geográfico intelectual e socialmente reconhecido que longe de fragmentar contribui ao enriquecimento da noção de totalidade social.

Palavras-chave: Teoria da ciência; Evolução do pensamento geográfico; Epistemologia da geografia.

\begin{abstract}
The evolution of the statute of geographic science in the concert of sciences and its relation with the construction of one knowing "space" socially recognized forms the central point of this essay. The constant production of new concepts for the traditional geographic categories is placed exactely in this dialectic between the construction of an independent geographic science and the evolution of the scientific hierarchies; socially recognized and whose synthesis would be an intellectual geographic knowledge that contributes to the enrichment of the notion of social totality.
\end{abstract}

Keywords: Theory of science; Evolution of the geographic thought; Epistemology of geography.

1 Mestre em Geografia Humana - USP e doutor em Geografia - UFSC. Professor do Departamento de Geociências da UEPG e do Programa de Mestrado em Gestão do Território da UEPG. E-mail: silvestre@uepg.br

Registro especial menção à professora Dra. Leila Christina Dias pelas brilhantes e inspiradoras aulas na disciplina de Seminários de Pesquisa, do Programa de Pós-Graduação em Geografia da UFSC, para quem também agradeço a revisão deste ensaio. 


\section{INTRODUÇÃO}

A coletânea organizada por Serres (1996) sobre a evolução do estatuto científico de disciplinas como física e química nos estimula a revisitar também a evolução da geografia enquanto campo autônomo do saber científico. Afinal, os conceitos e categorias mais caras à ciência geográfica - espaço geográfico, território, região, paisagem, rede - têm experimentado uma permanente mudança de significado na medida em que novos paradigmas teóricos são criados ou incorporados tendo por base os avanços das chamadas ciências afins. É assim que, por exemplo, foram desenvolvidos conceitos de região pela ótica da botânica, da geologia, da ciência política e, talvez com maior frequência, da economia. E não se passa algo diferente com os conceitos de território, paisagem e rede.

A história da epistemologia da ciência geográfica aponta que, por longo tempo, a evolução desta ciência aparece marcada por readaptações de referenciais teóricos e instrumentais conceituais de fora da geografia e que transparece nas pesquisas e textos produzidos por geógrafos. O objetivo deste ensaio é refletir sobre a natureza dessa relação entre ciência geográfica e ciências afins ao longo do tempo. Para tanto, recuperamos questões que não de hoje afligem aos geógrafos e filósofos da ciência: afinal, o reconhecimento do estatuto científico da geografia vem de seus métodos positivos ou do estabelecimento de uma visão integrada de mundo? A teoria geográfica ou espacial já está suficientemente edificada? A Geografia pode almejar o mesmo estatuto científico que ciências ditas mais nobres como física e economia? Responder definitivamente essas questões é seguramente meta mais difícil que constatar na história da epistemologia da geografia a permanência da problemática de uma teoria própria acabada e a constante reconstrução da identidade geográfica no concerto das ciências.

\section{AFINIDADES E HIERARQUIA CIENTÍFICA}

As afinidades teórico-conceituais entre as ciências estabelecem uma complexa hierarquia científica que tanto apresenta uma face positiva assentada no intercâmbio disciplinar quanto uma face negativa no momento em que cristalizam essas relações e trazem uma carga de valoração diferenciada para cada ciência. Nesse último sentido, mesmo na atualidade, a ciência geográfica está constantemente às voltas com discursos de primazia científica e social de outras ciências, como a economia e a sociologia.

Podemos exemplificar essa situação através do posicionamento do sociólogo P. Bourdieu (2001, p. 108) quando afirma que o conceito de região foi e continua "objeto de lutas entre os cientistas, não só os geógrafos é claro, que por terem que ver com o espaço, aspiram ao monopólio da definição legitima, mas também historiadores, etnólogos e, sobretudo desde que existe uma política de regionalização e movimentos regionalistas, economistas e sociólogos". Para Bourdieu (2001, p. 144), na "história social das categorias de pensamento do mundo social" a geografia estaria em nível inferior ao da economia em termos de validação ou reconhecimento social e se traduziria em contratos de pesquisa mais favoráveis a estes últimos, sobretudo nos trabalhos de planejamento territorial encomendados por instituições governamentais.

Ocorre que os contratos de financiamento público à pesquisa representam apenas uma parte da complexa equação que forma a validação social de determinado discurso científico. E esta equação envolve inclusive discursos acadêmicos como de P. Bourdieu, que também acabam por contribuir para a formação da vontade política e o destino das verbas públicas de pesquisa e planejamento. Afinal, na definição das regiões de planejamento importa menos a existência de critérios objetivos que a imposição de recortes territoriais e conceituais arbitrários em função da hierarquia científica estabelecida.

As problematizações que a sociedade coloca às ciências exigem o contato entre as disciplinas (o que não significa obrigatoriamente a instauração de um diálogo), e, em decorrência, o corpo teórico e conceitual de cada disciplina científica acaba inevitavelmente entrando em "luta pela legitimidade" com aquelas que se encontram pretensamente em níveis superiores da hierarquia. Gomes (1997) destaca o fato de que a constante recolocação da questão da natureza do conhecimento geográfico também tem obrigado a geografia a (re)pensar sua relações com as outras ciências. E é justamente no acomodamento dessas relações disciplinares que se manifesta o lugar da geografia na hierarquia científica.

Embora recorrentes na evolução da ciência geográfica, as tentativas de suprir suas carências teóricoconceituais específicas através da tomada de empréstimo de instrumentos conceituais e até metodológicos de outras ciências, isso não significa que os geógrafos devam aceitar uma aproximação "subalterna" às ciências afins e tampouco que não devam continuar avan- 
ALBUQUERQUE, E. S. de. O lugar da Geografia nas ciências e a questão da permanente...

çando na construção de um conhecimento geográfico autônomo capaz de enriquecer o próprio conhecimento científico em geral.

\section{A LONGA TRAJETÓRIA DO PAPEL SUBALTERNO DA GEOGRAFIA}

Nas origens da ciência moderna, a primazia das ciências naturais se impôs através da geologia e da biologia justamente por sua institucionalização pioneira. Afinal, melhor definidas no propósito de explicar a natureza do mundo a partir de sua materialidade e de modo a afastar de vez os postulados metafísicos (rompendo com qualquer resíduo religioso da ideologia feudal), essas ciências primazes (na qual incluiríamos a física) acabaram, naturalmente, influenciando as demais ${ }^{2}$. Nessas condições, os primeiros intercâmbios interdisciplinares para ciências retardatárias como geografia somente poderiam ter se desenvolvido de forma desigual ou assimétrica.

É na Alemanha de fins do século XIX que surgem as primeiras tentativas de sistematização conceitual e de definição de um objeto próprio da geografia por meio dos trabalhos de Alexandre von Humboldt, Friedrich Ratzel e Karl Ritter. Nesse momento inicial foi inevitável um "diálogo" mais profundo (ou mais exatamente "cópias") com os métodos e conceitos das ciências naturais, então mais estruturadas em termos epistemológicos. E embora o nascimento da geografia moderna tenha representando importante função de legitimação da unificação alemã e de seus projetos expansionistas, desse esforço inicial redundou apenas: "uma Geografia sistematizada que, apesar de assumir-se como campo autônomo de conhecimento científico, não chega a formular uma proposta de estudo sistemático, isolando um objeto especificamente seu" (MORAES, 1989, p. 15).

Nas primeiras décadas do século XX se desenvolve a chamada Escola Possibilista Francesa, centrada nos estudos de região na perspectiva da paisagem. Embora se opondo radicalmente ao "determinismo" e à "politização" da Escola Alemã, os geógrafos "possibilistas" também auxiliaram na construção da legitimação da ideologia da "missão civilizatória" francesa nas colônias de além-mar. E também a geografia francesa bebeu abundante das ciências afins, como sintetiza Robert Moraes (2002, p. 71) ao comparar Vidal de La Blache e F. Ratzel: "o fundamento positivista se aproxima nas concepções dos dois autores, e, vinculado a este, a aceitação de uma metodologia de pesquisa oriunda das ciências naturais".

Com efeito, a ideia de "meio geográfico" a partir das relações sociedade-natureza apareceu fortemente nestas duas escolas geográficas nacionais, ainda que na Alemanha com a mediação do Político (o "espaço vital" ratzeliano), e na França com a mediação da Cultura (os "gêneros de vida" lablachianos). Assim, era quase natural essa dependência inicial da geografia frente aos conceitos de outras disciplinas mais "evoluídas". A questão de uma ontologia do espaço ainda não estava colocada na medida em que a geografia ainda andava as voltas com uma visão metafísica de espaço: um espaço absoluto como se dotado de propriedades independentes dos fenômenos materiais ${ }^{3}$.

Mas esse fenômeno de transplante ou cópia de conceitos e métodos de outras disciplinas não foi privativo da geografia. Stengers (1996) no artigo "A afinidade ambígua: o sonho newtoniano da química do século XVIII" descreve a busca da autonomia científica da química e o modo como a física obstaculizou esse processo. Por longo tempo, os químicos modernos tentaram explicar as reações químicas diversas da mesma forma que os físicos explicavam a força de atração dos corpos, afinal Isaac Newton explicara desde a queda dos corpos nas condições terrestres até o comportamento orbital dos planetas através da gravidade (lei de atração dos corpos).

A afirmação da química enquanto campo científico autônomo viria por um caminho menos complicado, ligado aos interesses práticos da nascente e próspera indústria inglesa, quando pôde tranquilamente desvincular-se da necessidade da criação de leis como as físicas. Entretanto seu marco pioneiro foi na França, quando Lavoisier empregou a balança para estabelecer um maior controle das condições dos experimentos de reações químicas (daí sua suposta frase de que na natureza "nada se perde, nada se cria, tudo se transforma"), o que acabaria por elevar a química ao estatuto de ciência moderna (BENSAUDE-VINCENT, 1996).

2 Papel equivalente nas ciências sociais talvez possa ser atribuído à economia, que com a "descoberta" das leis fundamentais que regem a vida material dos homens contribuiu decisivamente para construir o domínio absoluto da razão moderna no campo das humanidades.

3 Como destaca o geógrafo Gomes (1997), a geografia tradicional aplicava um "kantismo empobrecido", o que se refletia inclusive nos estudos regionais através de formas apriorísticas de região. 
Evidente que a geografia tradicional não poderia apresentar a mesma utilidade que a química para a indústria moderna. Mas, em compensação, talvez tenha encontrado outra forma igualmente prática de validação, mais atrelada às estratégias territoriais do Estado moderno. Impossível deixar de destacar novamente a "geografia política" de F. Ratzel, em que já aparece uma proposta mais elaborada de autonomia da geografia quando destaca os princípios da localização e da extensão do espaço (projeção territorial a partir dos recursos naturais). De outra forma, também os famosos estudos regionais franceses promoveram especializações que levaram a novas disciplinas como Geografia Agrária e Geografia Econômica e que a medida que faziam mais e mais uso de ferramentas estatísticas e modelos matemáticos, acabaram por auxiliar nas atividades de planejamento do Estado.

\section{A VALIDAÇÃO DA GEOGRAFIA A PARTIR DAS ESTRATÉGIAS TERRITORIAIS DO ESTADO}

Com o declínio das guerras expansionistas e do sistema colonial europeu a função ideológica da geografia tradicional perdeu sua importância original. Assim, a busca por novos métodos instrumentais tornou-se fundamental para atender às novas demandas das instituições públicas. Com efeito, Robert Moraes (2002, p. 94-95) destaca a emergência do regime de acumulação capitalista baseada nos monopólios como causa primeira da defasagem dos produtos da ciência geográfica tradicional:

\begin{abstract}
O liberalismo econômico estava já enterrado; a grande crise de 1929 havia colocado a necessidade da intervenção estatal na economia. Haviam caído por terra, as teses da livre iniciativa, da ordem natural e autoregulada do mercado. Propunha-se agora a ação do Estado na ordenação e regulação da vida econômica. [...] A realidade do planejamento colocava uma nova função para as ciências humanas: a necessidade de gerar um instrumental de intervenção, enfim uma feição mais tecnológica. A Geografia Tradicional não apontava nessa direção, daí sua defasagem e sua crise.
\end{abstract}

A tradição geográfica na coleta e interpretação de dados em base regional ou nacional interessaria especialmente aos órgãos de planejamento do Estado cuja ação é eminentemente circunscrita a limites territoriais muito bem definidos. Na Europa, o método instrumental da "diferenciação de áreas" de A. Hettner (onde uma imensa gama de elementos naturais e sociais é reduzida a um conjunto de variáveis numéricas), e, nos Estados Unidos, a Escola do Meio-Oeste ao aproximar-se da sociologia funcionalista e da economia, representaram os primeiros passos no sentido do uso de métodos matemático-estatísticos pela ciência geográfica.

Talvez R. Hartshorne, como em Propósitos e Natureza da Geografia, tenha melhor definido esse período de transição ao anunciar que a validade científica da geografia estaria na definição de um método próprio e não de um objeto singular. A partir da década de 1950, a Geografia Quantitativa - centrada nas análises estatísticas - e a Geografia Sistêmica - no uso de modelos de análise de impactos ambientais, previsões climáticas e planejamento urbano e de bacia hidrográfica - foram as correntes mais desenvolvidas dessa nova proposta metodológica e cujas contribuições permanecem até os dias atuais.

Evidente que esse discurso geográfico mais técnico nem sempre gerou análises confortáveis ao sistema econômico e aos Estados nacionais. Mas também é verdade que essas perspectivas tampouco foram capazes de encaminhar uma solução definitiva para a questão da identidade e do estatuto científico da geografia, prosseguindo na busca de subsídios das ciências afins: "O método especificamente geográfico viria do fato de essa disciplina trabalhar o real em sua complexidade, abordando fenômenos variados, estudados por outras ciências" (MORAES, 2002, p. 87).

De que forma então os geógrafos conseguiram reconstruir sua inserção institucional e na comunidade acadêmica mesmo com métodos limitados? Primeiramente, é preciso reconhecer que o discurso e o instrumental mais técnico advindo do uso do sensoriamento remoto e de modelagens computacionais foram capazes de gerar per si uma maior "respeitabilidade" acadêmica e social. Segundo, os limites das teorias clássicas das ciências naturais (especialmente da física) e a quebra de paradigmas das ciências sociais generalizaram a crise de identidade científica. A globalização das atividades econômicas e da agenda política redefine a escala nacional, e, com ela, traz um sério limitante para os instrumentais de todas as ciências sociais. Inevitavelmente, essa nova situação rompe com o unilateralismo na relação da ciência geográfica com as demais ciências, para preparar o caminho do diálogo entre iguais. 
ALBUQUERQUE, E. S. de. O lugar da Geografia nas ciências e a questão da permanente...

\section{A CRISE DOS "SENHORES DA CIÊNCIA"}

O caráter utilitário se impôs sobre as dimensões contemplativas e narrativas para todas as ciências (o termo "ciência aplicada" é usado desde a física até a economia), o que já representa limites menos rígidos para a questão da autonomia científica. Mas também o ceticismo que se abateu sobre as ciências tradicionais amparadas em suas "meta-teorias" exige um intercâmbio real entre as disciplinas acadêmicas. Esse ceticismo atingiu, por exemplo, os físicos teóricos diante das dificuldades para uma Teoria da Unificação capaz de dar coerência ao conjunto das leis físicas já descobertas (a moderna teoria das Supercordas já começa a "fazer água" com modelos que reúnem 26 dimensões) ${ }^{4}$. Em outras palavras, a própria legitimidade atual da física parece advir menos da continuidade de avanços científicos na "fronteira da ciência" que pelo caráter aplicado de algumas de suas áreas como a física nuclear (fusão) ou a promissora supercondutividade.

Esse ceticismo atinge também a economia e a sociologia na medida em que nem o mercado nem as políticas públicas parecem instrumentos capazes de resolver os problemas sociais. Os economistas liberais percebem em número cada vez maior que a dinâmica dos mercados não permite a previsibilidade científica esperada; e os economistas marxistas reconheceram o fracasso das experiências socialistas no controle planejado da máquina produtiva total.

A boa novidade para a geografia é que os momentos de crise permitem a retomada da luta pela legitimidade científica das ciências subalternas, uma vez que escancaram os limites das ciências do nível superior da hierarquia. E, de fato, tanto a crise ambiental quanto as dificuldades surgidas no planejamento econômico e social têm representando excelentes oportunidades para uma inserção mais ativa dos geógrafos. As problematizações colocadas pela sociedade em cada época exigem das disciplinas científicas respostas diferenciadas, sendo que umas parecem mais que outras guardar a chave para abrir algumas portas ao encontro de soluções. Será a geografia uma dessas ciências da vez?

\section{A TEORIA SOCIAL CRÍTICA DIANTE DAS HIERARQUIAS CIENTÍFICAS}

Ainda que uma maior preocupação quanto a uma epistemologia da geografia tenha ocorrido tardiamente, mais exatamente a partir da década de 1960 (SANTOS, 1997; MACHADO, 1997), as propostas de superação da dicotomia entre geografia humana e geografia física e do saber geográfico fragmentado em geral encontraram na reconstituição da totalidade (o espaço geográfico) a partir do social seu "carro-chefe".

Num primeiro momento, a teoria social crítica aparece na geografia e nas ciências sociais em geral quase como mera transposição do pensamento da economia política marxista, não por acaso justamente quando a economia gozava de enorme prestígio através do planejamento econômico. O edifício teórico marxista parecia muito bem planejado, com a infraestrutura econômica e as superestruturas políticas e culturais (ideológicas). Ainda que a proposta fosse de uma dialética entre essas estruturas sociais, o resultado foi invariavelmente uma leitura do movimento social a partir das "leis do capital": o tempo e o espaço apareciam como a historicidade e a espacialidade decorrentes da relação capital-trabalho. Portanto, à geografia caberia o papel subalterno de desvelar as formas territoriais de extração da mais-valia e para tal empreitada dispunha do instrumental conceitual "já testado" pela economia política marxista.

No ápice do desenvolvimento de uma "geografia marxista", na década de 1970, ganharam destaque discursos de negação dos conceitos e categorias geográficas. Tornou-se famosa a crítica de Yves Lacoste (1977) de que o conceito de região teria se transformado num poderoso "conceito-obstáculo" para o avanço na teorização geográfica ao desviar o foco das relações de classe. Para outros ainda, como Markusen (1981), a região nem mesmo teria existência concreta, apenas os regionalismos (e ainda como expressão da ideologia classista). Ainda assim, o sentimento inicial foi de que a transposição direta das categorias analíticas marxistas propiciaria a esperada "unidade do pensamento geográfico" a partir do social.

Mas no momento seguinte, a própria legitimidade

4 A teoria das Supercordas é um modelo físico cujos elementos fundamentais são objetos unidimensionais que lembram a corda de violão, diferenciando-se do modelo tradicional de partículas de dimensão zero. A vibração destas cordas produziria a diversidade de fenômenos físicos conhecidos. 
científica da geografia passou a ser questionada; afinal, os economistas entenderiam melhor dos processos de regionalização e os sociólogos dos regionalismos! Para o sociólogo Pierre Bourdieu, ainda que a geografia tivesse herdado o monopólio da forma espacial, já não tinha estatuto científico relevante. Breve, mas extremamente temeroso, talvez esse tenha sido o momento histórico de maior crise de legitimidade da geografia moderna, resultando inclusive no questionamento de seu papel de "disciplina escolar" como explicitado pela proposta de reforma curricular francesa que desejava simplesmente abolir a disciplina de geografia.

Toda essa confusão envolvendo a geografia certamente não pode ser atribuída à filosofia marxista, mas antes a certas leituras reducionistas carregadas do viés economicista. Mas ainda está por ser realizado um amplo debate na comunidade geográfica acerca do "ambiente" favorável que os próprios geógrafos criaram para que essa situação chegasse a tal ponto. É preciso refletir seriamente se essa mera transposição do instrumental conceitual marxista para a geografia não ocorreu, outra vez, devido a nosso já longo histórico de dependência frente às ciências com métodos supostamente mais consolidados.

Felizmente, ainda em fins da década de 1970, surgiram as primeiras propostas que implicitamente questionavam essa quase completa subserviência metodológica da geografia à economia política. Nesse período, Milton Santos (1977, p. 12), ainda que sem romper com os pressupostos marxistas, propõe a re-fundação do conceito-método de formação econômica e social, agora compreendido como formação sócioespacial ${ }^{5}$ :

[...] $\circ$ interesse dos estudos sobre as formações econômicas e sociais está na possibilidade que eles oferecem de permitir o conhecimento de uma sociedade na sua totalidade e nas suas frações, mas sempre um conhecimento especifico, apreendido num dado momento de sua evolução. O estudo genético permite reconhecer, a partir de sua filiação, as similaridades entre F.E.S., mas isso não é suficiente. É preciso definir as especificidades de cada formação, o que a distingue das outras e, no interior da F.E.S., a apreensão do particular como cisão do todo, um momento do todo, assim como o todo reproduzido numa de suas frações.
Apesar de destacar a dimensão espacial, o conceito de formação sócioespacial ainda representa uma leitura de território enquanto "componente" do espaço econômico (modo de produção). Nesse ponto, precisamos nos perguntar se nesse estágio a proposta miltoniana já estava suficientemente madura para fazer avançar o projeto de uma geografia autônoma?!

\section{O CONSENSO DA COMUNIDADE GEOGRÁFICA EM TORNO DA TEORIA ESPACIAL MILTONIANA}

Nas duas décadas seguintes M. Santos propõe para a geografia um novo corpo conceitual próprio e bastante elaborado, mas vai muito além disto: a ideia da indissociabilidade do sistema de objetos e sistema de ações funda um método geográfico capaz de afirmar o espaço enquanto forma-conteúdo e dotado de várias racionalidades para além da esfera da produção propriamente dita:

\begin{abstract}
Objetos naturais e objetos fabricados pelo homem podem ser analisados conforme o seu respectivo conteúdo, ou, em outras palavras, conforme sua condição técnica, e o mesmo pode ser dito das ações, que se distinguem segundo os diversos graus de intencionalidade e racionalidade. (SANTOS, 1999, p. 20-21).
\end{abstract}

O espaço geográfico é finalmente alçado à condição de polo ativo no complexo movimento da totalidade social, possibilitando a reconstituição da totalidade social a partir de uma perspectiva espacial, quebrando com o monopólio do tempo e a exclusividade das categorias econômicas. Contudo, parte do consenso em torno da proposta miltoniana parece advir também da preservação de certos fundamentos marxistas em suas novas teorizações ${ }^{6}$. Quando M. Santos pensa o mundo como um conjunto de possibilidades abre diálogo com a ideia marxista de praxis. E mais ainda, quando destaca a tecnoesfera também sinaliza para a materialidade do mundo.

5 Maurício de Abreu (1996) recorda da participação destacada de Milton Santos na revista marxista Antipode, com a redação de artigos e coordenação de trabalhos. Mas esse momento também marca o inicio de suas reflexões quanto ao estatuto científico da geografia.

6 De acordo com o próprio Milton Santos (1999, p. 46): "Segundo uma frase muito frequentemente citada de Marx (Capital, I, p. 132, edição de M. Harnecker), 'o que distingue as épocas econômicas umas das outras, não é o que se faz, mas como se faz, e com que instrumentos de trabalho'." 
ALBUQUERQUE, E. S. de. O lugar da Geografia nas ciências e a questão da permanente...

Vamos aprofundar um pouco esses pontos. $\mathrm{Na}$ obra A ideologia Alemã (1845), Marx explicitava que a materialidade não precisava estar posta de forma completa por todos os pontos do globo para que a consciência social aflorasse. Da mesma forma, os objetos técnicos não precisam estar em todos os pontos do mundo para que sua universalidade afirme o mundo enquanto conjunto de possibilidades.

A herança marxista é nítida quando se percebe na proposta miltoniana que os territórios são produzidos justamente a partir do processo de valorização diferencial dos lugares (SANTOS, 2003, p. 142):

O espaço agrícola é, seletivamente, o receptáculo de dois tipos de capital: um capital novo, valorizado, que escolhe lugares privilegiados onde, ajudado pelo Estado, pode reproduzir-se melhor e mais rapidamente; e um capital desvalorizado, velho, que deve se refugiar nas atividades menos rentáveis, prejudicado ainda pela má qualidade ou mesmo pela inexistência de infra-estruturas.

As afinidades entre geografia miltoniana e o marxismo prosseguem através do conceito de meio técnico-científico-informacional, compreendido enquanto forma espacial complexa dos novos fixos e fluxos econômicos. Não poderia ser diferente, já que ciência, técnica e informação constituem o meio moderno para o movimento do capital:

Em nossos dias, a informação, sobretudo nas grandes firmas, poderia ser contabilizada como capital orgânico, imprescindível para a criação e reprodução de maisvalia e exigente, a cada dia, de atualização. (SANTOS; SILVEIRA, 2001, p. 99).

Essas técnicas se efetivam em relações concretas, relações materiais ou não, que as presidem, o que nos conduz sem dificuldade à noção de modo de produção e de relações de produção. (SANTOS, 1997, p. 61).
[...] a impulsão que recebem esses conjuntos técnicos atuais (ou suas frações) é única, vinda de uma só fonte, a mais-valia tornada mundial ou mundializada, por intermédio das firmas e dos bancos internacionais. (SANTOS, 1997, p. 125).

Demonstrada a existência de profundas afinidades entre a geografia miltoniana e a filosofia marxista não implica em deixar de reconhecer que M. Santos considera a produção do território para além da demonstração da seletividade territorial operada pelo capital na produção de valor acrescido ${ }^{7}$. A categoria lugar emerge em M. Santos com uma força nunca antes vista na geografia, abrindo a possibilidade para uma nova percepção (e ação) no mundo da globalização.

Desse jogo dialético entre afinidades e autonomia a geografia miltoniana pôde preservar ao mesmo tempo em que atribuía novos significados ainda para conceitos e categorias da geografia tradicional, como espaço geográfico (meio técnico-científico-informacional), região (regiões de mando e do fazer, regiões concentradas), paisagem (aspecto visível do real), dentre outros. Razão mais que suficiente para concordarmos com Maurício de Almeida Abreu, quando em um ensaio para o livrohomenagem ao trabalho de Milton Santos O mundo do cidadão, um cidadão do mundo, destaca que toda a comunidade geográfica brasileira tem o compromisso de reconhecer na obra desse brasileiro a recomposição de sua autoestima enquanto saber científico:

\footnotetext{
Pelo seu fecundo esforço de teorização, que não deixa de levar em conta os avanços teóricos vindos de outras áreas do conhecimento, mas que resiste bravamente aos cantos de sereia que atraem o viajante para outros rumos, que podem acabar transformando o seu trabalho em qualquer outra coisa, menos em geografia. Seu compromisso é com a teorização sim, mas com a teorização geográfica. Sabe que um conhecimento científico só se afirma quando se impõe a si mesmo, e é por isso que faz ouvidos de mercador às argumentações fáceis de que as barreiras disciplinares já não são importantes hoje. (ABREU, 1996, p. 47).
}

7 Evidente que isso não significa a supressão de todo o debate mesmo para certas questões onde é possível apontar a existência de afinidades com o marxismo, como na proposta miltoniana de periodização da formação do território brasileiro em função do estágio de desenvolvimento técnico (SANTOS; SILVEIRA, 2001). Para certas perspectivas do materialismo dialético, desde o momento de exploração direta da natureza tropical brasileira os elementos técnicos já estavam presentes (ainda que não na forma automatizada), e, portanto, seria arbitrária a diferenciação entre uma suposta fase de protounificação do território nacional (ideia que remete à tese dos "arquipélagos econômicos") e uma fase tardia de integração nacional plena (AUED; ALBUQUERQUE, 2005) 
Se a produção miltoniana ainda não conquistou seu merecido espaço intelectual na comunidade geográfica internacional (ABREU, 1996) - o que remete para as barreiras nacionais já conhecidas em nosso meio desde as querelas dos "possibilistas franceses" diante da geografia política alemã - consegue recuperar a estima dos geógrafos brasileiros e nos fazer reivindicar um novo estatuto na hierarquia científica. Resta esperar que a geografia possa continuar a manter esse "monopólio da técnica" na explicação da natureza do mundo contemporâneo.

\section{CONSIDERAÇÕES FINAIS}

O fortalecimento da "visão espacial" e do conceito de território nas últimas décadas (culminando na formulação das "teorias espaciais críticas" de E. Soja e M. Santos) representa um novo momento da geografia na hierarquia científica. Mas essa "audácia" não representa propriamente novidade histórica na evolução dessa disciplina, como demonstram as pretéritas pretensões "enciclopedistas" e de "síntese do conhecimento universal", ambas assentadas numa visão quase telúrica das relações sociedade-natureza.

Também permanece em aberto até quando esse consenso produzido em torno da obra miltoniana será capaz de cimentar a pluralidade de interesses que residem em nossa disciplina e mesmo sem considerar as bandeiras dos "geógrafos físicos". A questão de uma ontologia do espaço é polêmica e de difícil solução, o que explica também essa permanente necessidade histórica de produção de novos significados para as categorias geográficas, talvez até mais que em outras ciências. Contudo, é impossível deixar de reconhecer que Milton Santos instaurou uma revolução na terminologia geográfica ao finalmente dotá-la de um corpo teórico-conceitual hermeneuta, e tudo isto justamente num momento histórico extremamente penoso particularmente para as ciências sociais.

Justamente porque a leitura dos fenômenos espaciais (assim como dos fenômenos temporais) depende de um elemento estruturador para atribuir sentido aos eventos dispersos, que a geografia buscou historicamente suprir essa carência nas ciências afins. Milton Santos logrou encontrar um precioso objeto ainda não reivindicado pelo monopólio científico e, com êxito, reivindicou sua apropriação pela geografia: a técnica. Quando meras coordenadas geográficas ou recortes políticos não mais garantiam a validação do saber geográfico, os objetos e o meio técnico anunciaram novas possibilidades de avançar no entendimento da produção dos territórios.

Cabe a atual geração de geógrafos fazer essa nova herança de uma geografia autônoma avançar no espaço institucional da academia, do poder público e da sociedade em geral. Sempre com o espírito de cooperação interdisciplinar e não com arrogância, afinal, o conhecimento talvez avance não apenas pela descoberta de "leis" próprias em cada ciência, mas também por uma maneira particular de encaminhar a questão das afinidades e hierarquias científicas.

\section{REFERÊNCIAS}

ABREU, M. de A. Sobre Milton Santos e sobre a crescente auto-estima da geografia brasileira. In: SOUZA, M. A. (Org.). O mundo do cidadão, um cidadão do mundo. São Paulo: Hucitec, 1996, p. 35-48.

AUED, I. M.; AlBuquERQUE, E. S. de. O método da desconstituição do capital e a Geografia. Terra Livre, São Paulo, n. 24, p. 43-60, 2005.

AUED, I. M. Marxismo e Geografia. In: ALBA, R. S. et al. O ensino da Geografia no novo milênio. Chapecó: Argos, 2002, p.13-58.

BENSAUDE-VINCENT, B. Lavoisier: uma revolução científica. In: SERRES, M. (Org.). Elementos para uma história das ciências II. Do fim da idade média a Lavoisier. Lisboa: Terramar, v. 2, 1996, p. 197-221.

BOURDIEU, P. O poder simbólico. Rio de Janeiro: Bertrand Brasil, 2001.
GOMES, P. C. da C. Geografia fin-de-siécle: o discurso sobre a ordem espacial do mundo e o fim das ilusões. In: CASTRO, I. E. de; GOMES, P. C. da C.; CORREA, R. L. (Orgs.). Explorações geográficas. Rio de Janeiro: Bertrand Brasil, 1997, p. 13-43.

HARTSHORNE, R. Propósitos e Natureza da Geografia. São Paulo, Hucitec, 1936. (trad. 1966).

LACOSTE, Y. El establecimento de un poderoso conceptoobstáculo: la region. In: LACOSTE, Y. (Org.). Geografia - un arma para la guerra. Barcelona: Anagrama, 1977.

MACHADO, M. S. Geografia e Epistemologia: um passeio pelos conceitos de Espaço, Território e Territorialidade. Território, n.1, p. 17-32, jan.1997.

MARKUSEN, A. Regionalismo: um enfoque marxista. Espaço e Debates. São Paulo: Cortez, v. 1, n. 2, p. 63-100, 1981. 
ALBUQUERQUE, E. S. de. O lugar da Geografia nas ciências e a questão da permanente...

MARTINS, L. L. Friedrich Ratzel hoje: a alteridade de uma geografia. Revista Brasileira de Geografia. Rio de Janeiro, v. 54, n. 3, p. 105-114, jul./set. 1992.

MARX, K.; ENGELS, F. A ideologia alemã. São Paulo: Martins Fontes, 2002. [1845]

MORAES, A. C. R. A gênese da Geografia Moderna. São Paulo: Hucitec; Edusp, 1989.

Geografia: Pequena história crítica. São Paulo: Editora Annablume/Hucitec, 2002.

PRADO JUNIOR, C. História econômica do Brasil. São Paulo: Brasiliense, 1945.

SANTOS, M.; SILVEIRA, M. L. O Brasil: território e sociedade no início do século XXI. Rio de Janeiro: Record, 2001.

SANTOS, M. Sociedade e espaço: a formação social como teoria e como método. Boletim Paulista de Geografia. São Paulo, n. 54, p. 81-100, jun. 1977.
(1979).

Economia espacial. São Paulo: Edusp, 2003

Técnica espaço tempo: globalização e meio técnicocientífico-informacional. São Paulo: Hucitec, 1997.

A natureza do espaço: técnica e tempo, razão e emoção. São Paulo: Hucitec, 1999.

SERRES, M. (Org.). Elementos para uma história das ciências II. Do fim da idade média a Lavoisier. Lisboa: Terramar, 1996. v. 2.

STENGERS, I. A afinidade ambígua: o sonho newtoniano da química do século XVIII. In: SERRES, M. (Org.). Elementos para uma história das ciências II. Do fim da idade média a Lavoisier. Lisboa: Terramar, v. 2, 1996, p. 149-166. 
